\title{
Maximum water level calculation based on 2- dimensional DELFT-3D model, the case study of the Oka river
}

\author{
Pavel Terskii ${ }^{1,2 *}$,Elizaveta Rakcheeva $^{2}$, Maksim Kharlamov $^{1}$, Andrey Pavlovskiy ${ }^{2}$, and \\ Igor Zemlyanov ${ }^{2}$ \\ ${ }^{1}$ Lomonosov Moscow State University, 1 Leninskie Gory, 119991, Moscow, Russia \\ ${ }^{2}$ Zubov State Oceanographic Institute, 6 Kropotkinskiy lane, 119034, Moscow, Russia
}

\begin{abstract}
This research represents methodical approach and main results of water level hydrodynamic modeling for real summer low-water season and extreme spring flood of $1 \%$ probability. The object of modeling is 105 $\mathrm{km}$ length section of the Oka River in Moscow region between Kashira and Kolomna urban districts. Modeling object includes also the Moscow River section downstream the Severka River mouth. Two-dimensional hydrodynamic model constructed using DELFT-3D. To build the model we used the detailed elevation model and hydrological conditions based on in-situ measurements in 2019, special estimated discharge and water level time-series of $1 \%$ exceedance probability based on reference year observations and distributed Chezy coefficient calibration. The model implementation resulted in the actual detailed distribution of the water discharge, velocity and level along the Oka River section (including the downstream Moscow River) for low-water and extremely high water periods. These results are used for the flood zone delineation in the Kashira and Kolomna urban districts.
\end{abstract}

\section{Introduction}

Hydrological processes may cause economic losses and social risk in some cases of their dangerous natural conditions. These days Russian Federation has a relatively new regulation - the Government Decision \#360 on the Flood zones delineation and regulation. "Flood zone" term means the area near the water body, which can be flooded with its water with certain probability. This document spells out the activities and sequence of actions to calculate and delineate flood zones. These zones should be introduced into the Russian State property register and should become the regulating lines for different kinds of human activities in floodplains. That is why maximum water level and its distribution must be calculated hydrologically correct and precise.

The object of modeling is $105 \mathrm{~km}$ length section of the Oka River in Moscow region between Kashira and Kolomna urban districts and the Moscow River section downstream the Severka River mouth and Severka dam on the Moscow River (Fig. 1). The Oka river

\footnotetext{
* Corresponding author: pavel tersky@mail.ru
} 
bed is 200-500 m wide, straight or with some branches, depths are 5-6 $\mathrm{m}$ in general. The valley is wide with wide floodplain. Low-water period velocity is about $0.5-0.8 \mathrm{~m} / \mathrm{s}$. The second part of XX century is characterised with river bed careers development, which provided sand and gravel for construction [1]. This activity lead to river bed and water level changes reflected in the water surface profile changes.

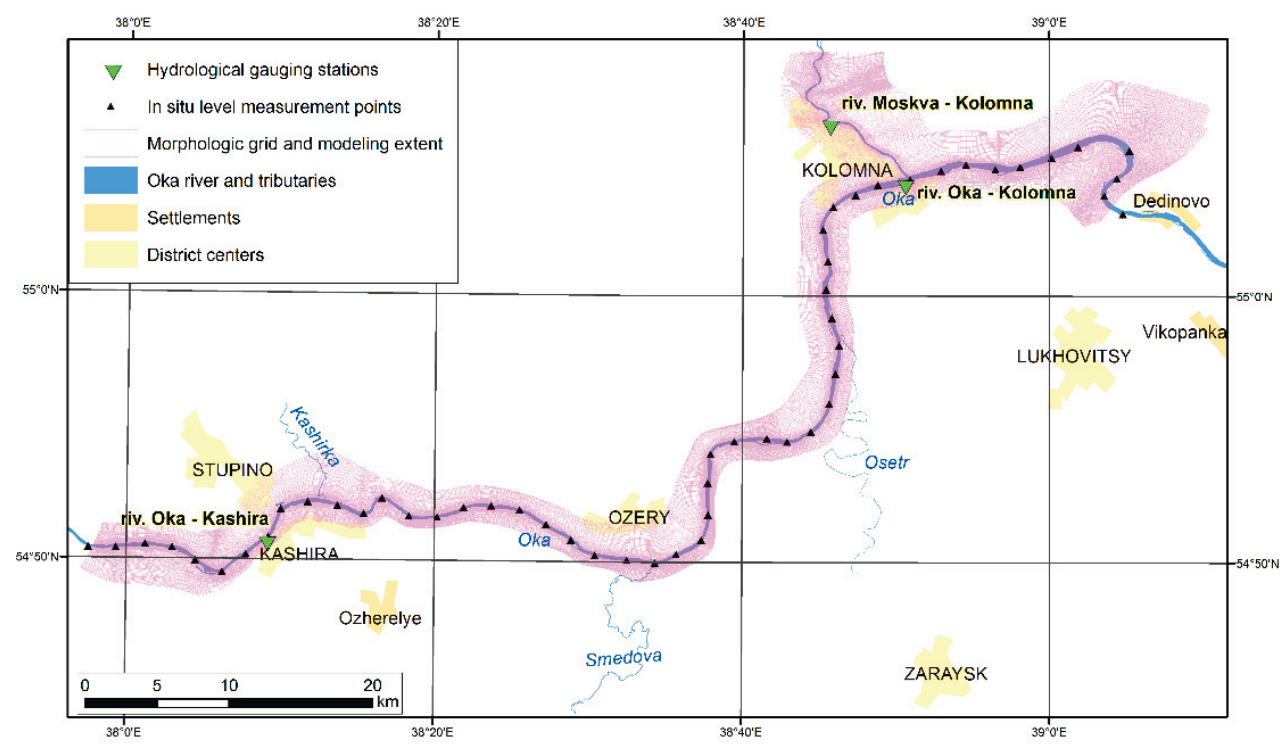

Fig. 1. The investigated part of the Oka River and modelling borders.

The investigated part of the Oka river is covered with several gauging stations: Oka river - Kashira, $927 \mathrm{~km}$ from mouth (daily water level and discharge are being measured), Oka river - Kolomna, $855 \mathrm{~km}$ (water level only), Moscow river - Kolomna, $5.5 \mathrm{~km}$ (water level) and Osetr river - Markino, $42 \mathrm{~km}$ (water level and discharge).

Oka and Moscow river valleys are settled rather dense in Moscow Region. Kashira and Kolomna cities are situated near the rivers. The main goal of the research is to provide the detailed actual and fresh quantitative understanding of high water level values and their generation during the extreme flood period of $1 \%$ exceedance probability ( $1 \%$ flood) based on two-dimensional model. This information is vital for further correct flood zone delineation and human activities planning [2].

\section{Materials and methods}

The main sequence of the research is as follows. The first step is choosing the tool (model), setting the interim objectives, collecting the field-based and archive data. The second step is building the basis of the model and setting it up for low-water period supported with the detailed data. The third step is developing the strategy of the model calibration for the lowwater period and conducting it. The fourth step is running the model for $1 \%$ flood reference period and validation. Results should include water level distribution, roughness distribution analysis and hydrological conditions estimation during the extreme spring flood period.

Two-dimensional hydrodynamic model for the investigated Oka and Moskva river parts built up using DELFT-3D tool and DELFT3D-FLOW extension [3]. Morphologic grid for 
finite difference approximations is regular curvilinear and orthogonalized. Time step for low water period is $0.10 \mathrm{~min}$, for flood $-0.25 \mathrm{~min}$. The inflows of Oka River, Moscow River and three main tributaries of the Oka River were used as the upstream boundary conditions. As the downstream boundary condition, we used water level. The mean low water level was set as the baseline condition. The model calibrated for low-water stable period using the field data and observed water levels on gauging stations by matching distributed riverbed Chezy coefficient (C). C for floodplain was set uniform.

Field in-situ measurement data was obtained in summer 2019. This data includes detailed water level measurements every 2 kilometres along the river, water discharges and detailed depth measurements. Other high quality data, such as detailed valley relief and also water levels and discharges of $1 \%$ flood at the Roshydromet gauging stations, was obtained by Zubov State Oceanographic Institute in 2019 [4]. Digital Elevation Model (DEM) was prepared based on different sources for the riverbed and floodplain. DEM has spatial resolution of $10 \mathrm{~m}$ built using UTM37N projection in the absolute geoid heights (Baltic system). Riverbed model built on hydrological survey data supported with geodetic water level measurements. To build DEM for banks and floodplain special aerial altimetry remote sensing data was obtained.

Estimated flood runoff time series of $1 \%$ probability were calculated based on reference spring flood of 1970 which is the closest to $1 \%$ probability by the runoff peak value. These calculations made based on Oka-Kashira and Osetr-Markino daily time series using the standard approach [5] and corrected with the actual values of $1 \%$ discharge. Using this approach all upstream boundary time series were produced by calculating daily discharge values and their time coordinate for the period of Apr 5 to May 6 1970. Downstream boundary condition time series were set up using the 1970 spring flood daily levels at OkaKolomna and corrected with the actual $1 \%$ water level for this station (because of riverbed erosion since 1970) and water surface slope.

Evaluation of the model performance was conducted with statistical approach by comparing measured and calculated water levels (51 points) for low-water period. The model validation was made for the $1 \%$ probability spring flood by comparing simulated water levels with calculated ones at the few Roshydromet gauging stations. Then, if validation was assessed as satisfactory, the results of calculated water level distribution were discussed and implemented.

\section{Results and discussion}

Water level distribution calculated for low-water period with different type of roughness input proved the distributed $\mathrm{C}$ approach. The developed pre-calibration routine was made by calculation of water level distribution based on four different uniform roughness Chezy coefficient (C), which were chosen inherently more and less then optimal for the riverbed in low-water period (Fig. 2). 


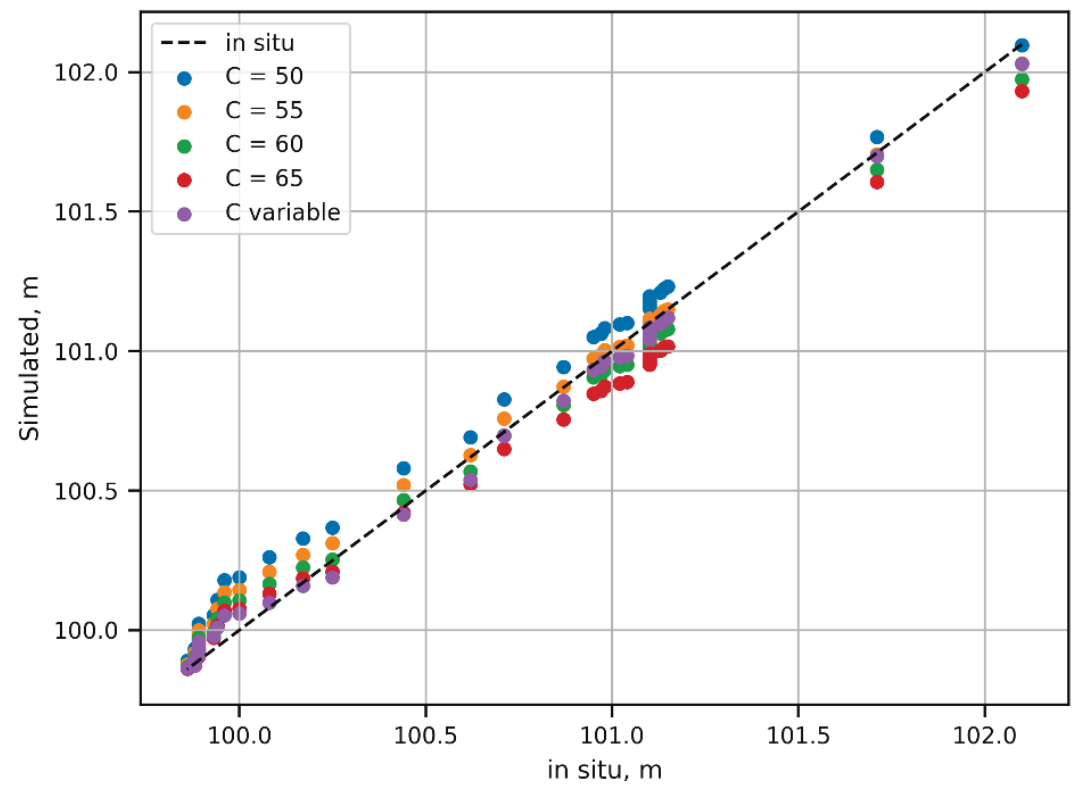

Fig. 2. Understanding and matching Chezy coefficient (C) based on comparison of simulated and in situ measured water levels.

Then we could recognise the zones to increase or decrease $\mathrm{C}$ value and regionalize it based on water level profile, river valley and channel zoning (Fig. 3).

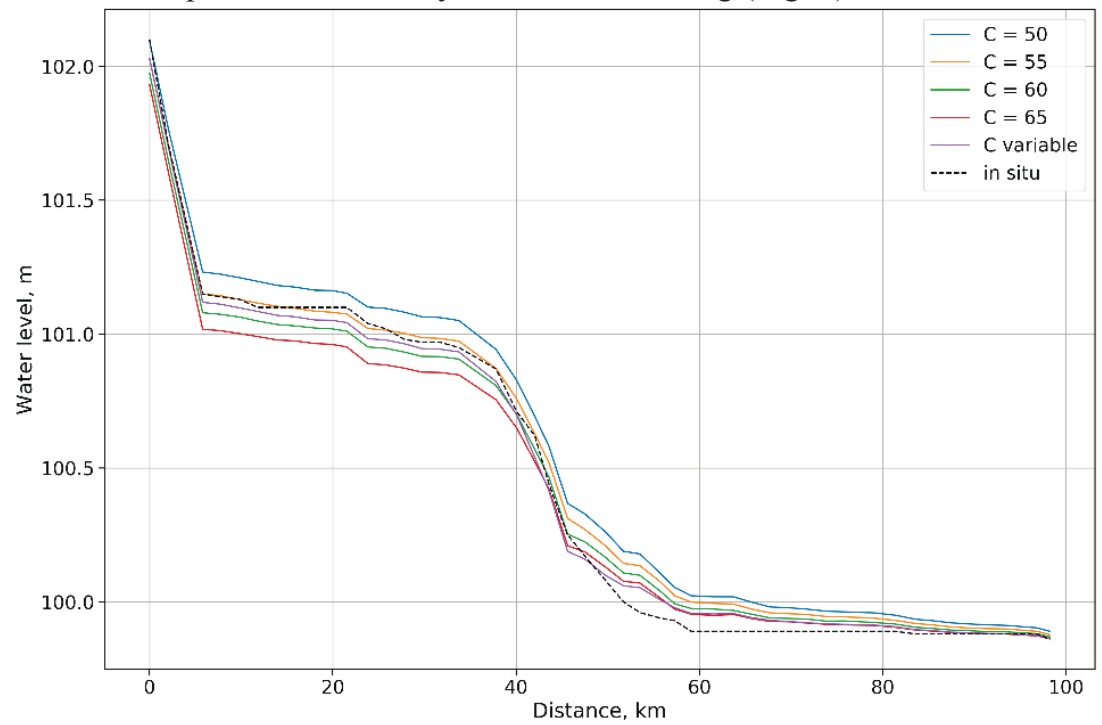

Fig. 3. Measured water level profile in comparison with simulated based on different Chezy coefficient.

Therefore, $\mathrm{C}$ was set variable from 50 for usual bending sandy parts of river channel up to 70 for straight and roll parts. It brings the best model performance (Table). 
Table. Model performance for low water period with different types and values of uniform and variable $\mathrm{C}$ (metrics chosen according to [6])

\begin{tabular}{|c|c|c|c|c|c|}
\hline Metric & $\mathbf{C = 5 0}$ & $\mathbf{C}=\mathbf{5 5}$ & $\mathbf{C}=\mathbf{6 0}$ & $\mathbf{C}=\mathbf{6 5}$ & $\mathbf{C}$ variable \\
\hline MAE & 0.089 & 0.047 & 0.055 & 0.071 & 0.034 \\
\hline MSE & 0.010 & 0.004 & 0.004 & 0.008 & 0.002 \\
\hline RMSE & 0.099 & 0.064 & 0.063 & 0.087 & 0.041 \\
\hline bias & 0.088 & 0.040 & -0.001 & -0.035 & -0.001 \\
\hline NS & 0.974 & 0.989 & 0.989 & 0.980 & 0.995 \\
\hline R2 & 0.995 & 0.996 & 0.997 & 0.997 & 0.998 \\
\hline
\end{tabular}

For the low-water summer period in situ observations and simulated water levels both show that Oka River water surface profile is stepped (has two sections with steeper surface) which are caused by geological preconditions and also in-channel sand quarries. During the spring flood of $1 \%$ probability the water surface profile is much straighter and water slope gradient becomes almost constant, slightly reducing downstream to the Moscow River mouth.

For the flood period, $\mathrm{C}$ for floodplain begins to make sense and can be used. It was set uniform as 40 and it brought satisfactory results. We believe the floodplain $\mathrm{C}$ is not very sensitive because the most part of discharge runs through the riverbed section against the floodplain one. This conclusion is proved by simulated (and also well known) water velocity and discharge distribution between riverbed and floodplane.

Simulated $1 \%$ water levels at the moment of the flood peak were examined at the gauging stations Kashira and Kolomna with calculated ones (Roshydromet). Errors are $0.021 \mathrm{~m}$ and $+0.054 \mathrm{~m}$ respectively. These errors are considered as satisfactory for model implementation. The flood wave was simulated with the model to assess the process of river valley volume filling and pouring during the flood period. Water level profiles at the phase of increase are consequently lower than at decrease phase (Fig.4). River valley has a huge empty volume, which is being filled during the flood period.

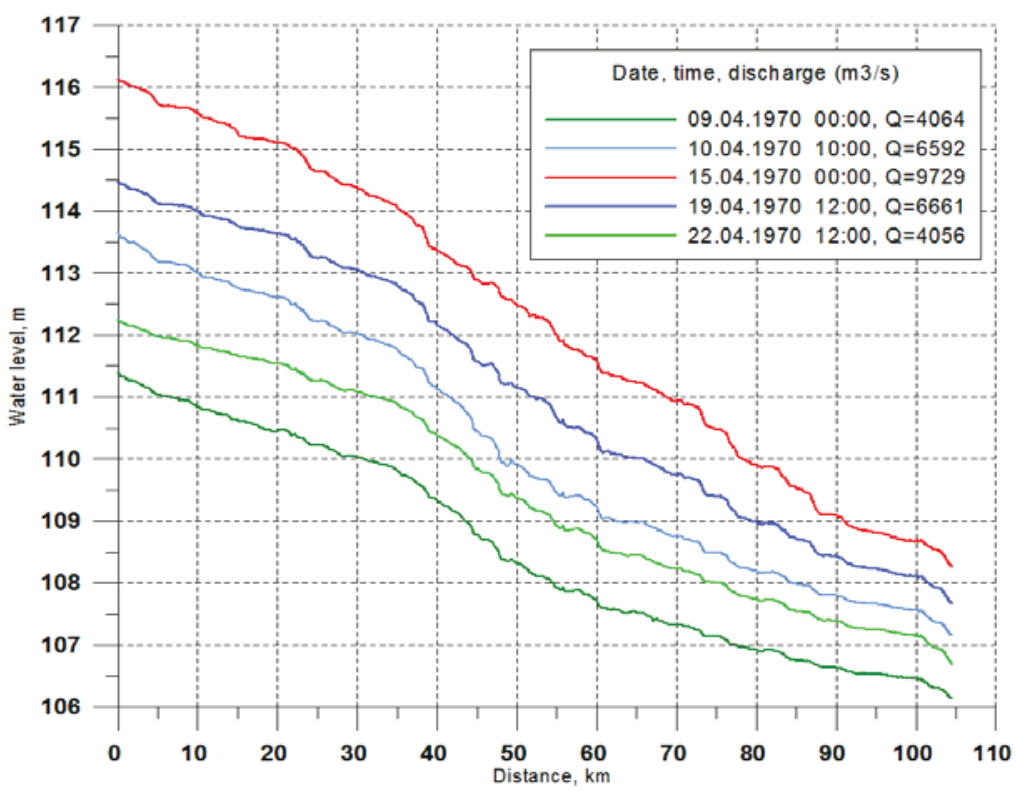

Fig. 4. Simulated water level profile of the Oka river during the increase, peak and decrease of flood wave in reference period April 1970 according to the upper daily inflow at Kashira station. 


\section{Conclusions}

The model implementation resulted in the actual detailed distribution of the water discharge, velocity and level along the Oka River section (including the downstream Moscow River) for low water and extremely high water periods. These results are used as the basis for the $1 \%$ flood zone delineation in the Kashira and Kolomna districts.

Further perspectives of the model implementation are scenario calculation of water level and velocity distribution caused by human activities in river valleys. New construction in floodplain, extraction of riverbed material and changes in dam regulation will affect hydrological regime. This effect cannot be measured in ungauged sections of the river and cannot be rapidly reflected in statistical characteristics but can be simulated with the model.

The model may be improved by using more detailed and proved hydrological input. Hydrological modeling is one of the modern options to simulate discharge time series for ungauged tributaries. Further calculation of water level and discharge of $1 \%$ probability needs more detailed $\mathrm{C}$ distribution. It is possible with accurate analysis of the flooded landscape types.

This research was supported by the State Oceanographic Institute under the governmental contract №2412 between the State Oceanographic Institute (SOI) and the Government of Moscow Region. We are thankful to the members of Soil Erosion Lab at Lomonosov Moscow State University (LMSU): Leonid Turykin, Pavel Golovlyov and Dmitriy Botavin, to researchers of SOI and LMSU: Mikhail Fatkhi, Anna Yakimova, Evgeniya Borshenko, Denis Mishin and Ivan Kopeykin, who took part in field work in this region in 2019.

\section{References}

1. P.V. Efremov, A.P. Chaliy, Proceedings of the tenth international symposium on river sedimentation, 55-59 (2007)

2. P.N. Terskii, M.O. Fatkhi, A.S. Tsyplenkov, I.V. Zemlyanov, A.E. Pavlovskiy, Georisk, 3, 20-29 (2017)

3. https://oss.deltares.nl/web/delft3d

4. Report with calculation of maximum discharge and water level of 1,3,5,10,25 and $50 \%$ probability for the gauges Pavlovskiy Posad (Klyazma river), Kolomna (Moscow river), Zaozerye (Moscow river), Bol.Alekseevskoe (Severka river), Kashira (Oka river), Strelkovskaya Fabrika (Pakhra river), Dorka river mouth) 26 pp. (Central Directorate of Hydrometeorological Service 2019)

5. Standard approach 33-101-2003 Determination of design hydrological performance (2004)

6. D. Wackerly, W. Mendenhall, R. Scheaffer, Mathematical Statistics with Applications (Belmont, CA, USA: Thomson Higher Education. ISBN 978-0-49538508-0 2008). 